\title{
DISCURSOS DE RESISTENCIA: DO PARATEXTO AO TEXTO. OU VICE-VERSA?
}

\author{
Beth BRAIT*
}

- RESUMO: O objetivo desta pesquisa é discutir estratégias de discursos de resistência que tomam como objeto de enfrentamento à ditadura militar vigente no Brasil no período compreendido entre as décadas 1960 e 1980, cujas sequelas se fazem sentir até hoje. Dentre esses discursos, que não cessam de emergir em diversas esferas, por meio de diferentes gêneros, o discurso literário será entendido como um dos que, mobilizando memória individual e coletiva, pela via de documentos e/ou relatos, procura desacobertar e fazer conhecer os efeitos devastadores dos anos de chumbo. Com base em fundamentação teórica oferecida pela perspectiva dialógica do discurso, as narrativas K. Relato de uma busca (KUCINSKI, 2012) e Os visitantes (KUCINSKI, 2016b), do jornalista e escritor Bernardo Kucinski, são consideradas como sequência discursiva articulada, na medida em que a segunda retoma a primeira, instaura uma interação polêmica e possibilita a observação dos valores em tensão que organizam o todo e delineiam faces de um projeto discursivo e do sujeito que o enuncia. Para efeito deste artigo, é destacada a relação dialógica estabelecida entre textos e paratextos, uma das estratégias do discurso literário de resistência que, pela instauração de vozes, busca respostas para acontecimentos escamoteados e para formas possíveis de presentificá-los pela linguagem.

- PALAVRAS-CHAVE: Enunciados de resistência. Paratexto. Estilística discursiva. Heterodiscurso. Prosa brasileira. Bernardo Kucinski.

\section{Considerações necessárias}

[...] o que passou efetivamente passou, mas há alguma coisa que não passa, alguma coisa que passa sem passar completamente, perpétuo presente em rotação. Octavio Paz (1984, p.239)

Aqueles eram mesmo anos inverossímeis.

Julián Fuks (2015, p.136)

Se hoje os tempos estão confusos e difíceis, com profundo estranhamento diante de vozes que parecem desconhecer as agruras vividas pelo país em tempos ditatoriais,

\footnotetext{
Pontifícia Universidade Católica de São Paulo (PUC-SP), Programa de Estudos Pós-Graduados em Linguística Aplicada e Estudos da Linguagem e Programa de Estudos Pós-Graduados em Literatura e Crítica Literária. São Paulo - SP - Brasil. Departamento de Linguística. bbrait@uol.com.br. ORCID: 0000-0002-1421-0848.
} 
basta voltar a discursos motivados pela recente ditadura militar brasileira, que teve seu início há pouco mais de meio século (1964), com duração de mais de duas décadas. Em relação a ela, não cessam de emergir discursos de diferentes esferas que, mobilizando a memória, via documentos e/ou relatos, pouco a pouco desacobertam, fazem conhecer e expõem os efeitos devastadores daqueles anos de chumbo, que se fazem sentir até hoje. Ainda há mortos insepultos, ocultados especialmente pelo discurso oficial, assim como pela frágil política de desvendamento dos intrincados subterrâneos do poder militar e de seus apoiadores. Uma prova dessa história que nunca acaba é o documento escrito por William Egan Colby, em 11 de abril de 1974, quando era diretor da Agência Central de Inteligência (CIA), e que os brasileiros tomaram conhecimento recentemente: 10 de maio de 2018.

Essa prova oficial escancara uma terrível realidade em relação ao presidente Ernesto Geisel, que governou o Brasil de 1974 a 1979. Embora ninguém tivesse ilusões em relação aos presidentes da época do regime militar, atribuía-se a ele o fato de seu governo ter sido marcado pelo início de uma abertura política e pela amenização do rigor do regime militar brasileiro. Essa ideia está exposta em muitos livros de história, manuais, repetindo-se continuamente como "fato". De acordo com esse documento, entretanto, que vem a público após 44 anos de sua redação, Geisel não apenas sabia das atrocidades do regime que temia uma mudança democrática e procurava retardála por meio da tortura e do extermínio, mas era conivente com o que acontecia, tendo autorizado a continuidade da política de assassinatos de adversários.

É nesse sentido que os discursos sobre a ditadura atuam, ainda hoje, como uma forma de resistência, proclamando que "o que passou efetivamente passou, mas há alguma coisa que não passa, alguma coisa que passa sem passar completamente, perpétuo presente em rotação", para utilizar as palavras de Otávio Paz (1984, p.239). Se um documento oficial, assinado por uma autoridade internacional de inteligência, tem legitimidade e poder para impor uma mudança nos registros da história brasileira, outros discursos, sem a dimensão oficial de uma prova incontestável, encontram formas de apontar para versões da história dessa recente ditadura militar que estão, no mínimo, perdidas entre as profundas e ocultas dobras do discurso oficial.

Dentre esses discursos, que se constituem por meio de diferentes gêneros, com circulação em diferentes esferas, o literário será tomado aqui como aquele que mantém "relação de reciprocidade e interdependência entre os diversos campos da cultura" (BAKHTIN, 2017, p.11-12) e "se revela, antes de tudo na unidade diferenciada da cultura da época de sua criação" (BAKHTIN, 2017, p.16). Isso significa que, por meio do discurso literário de resistência, algumas particularidades da cultura brasileira de ao menos dois momentos estarão em jogo, em tensão, tocando-se no limiar, nas fronteiras temporais, espaciais, sociais, afetivas. Ou seja, dimensões que sofreram a intervenção da ditadura, sendo por ela afetadas, se defrontam com documentos e discursos atuais que enfrentam e confrontam o doloroso passado. Juntando-se a isso o fato de que os gêneros, artísticos ou não, "acumulam formas de visão e assimilação de determinados aspectos do mundo" (BAKHTIN, 2017, p.16), a enunciação da resistência, o enunciado 
concreto que a sustenta e concretiza, e que inclui necessariamente o objeto que a propulsiona (no caso os desmandos fatais, alucinados e inverossímeis dos tempos da ditadura), debate-se entre ao menos dois polos em intersecção, em tensa interação.

De um lado, a necessidade do resgate, da reconstituição de acontecimentos que precisam ser falados, escritos, descritos, analisados de forma a serem conhecidos, reconhecidos, divulgados e, se possível, compreendidos na complexidade de suas várias dimensões. Esse processo se dá por meio da memória de um sujeito, social, histórico, discursivo, e pode ser auxiliada ou fundamentada por documentos e/ou depoimentos de outras memórias enunciadas. De outro, como consequência dessa necessidade vital, histórica, ética, há o aspecto que diz respeito à linguagem a ser mobilizada para realizar o resgate dos fatos dolorosos, momento enunciativo-discursivo que, invariavelmente, aponta para a quase impossibilidade do falar sobre eles, de lhes dar existência por meio de palavras.

Essas razões acabam por definir as particularidades do gênero assumido pela prosa de resistência que pode oscilar entre a tentativa de relato documental e a estetização, ficcionalização de um passado que se reflete e refrata no hoje, no agora e, perversa e permanentemente, coloca o enunciador no centro de uma luta também com a linguagem, com as palavras, com os gêneros. Pela força dessa contingência, nos discursos literários de resistência, a linguagem é tematizada de várias maneiras, expondo a (in)capacidade do sujeito enunciador e do próprio discurso de tocar esse "acabado que não cessa de continuar", pontificado por sequelas, por vestígios. Por vezes, aí se inclui a culpa e a insegurança discursiva dos que, tendo sobrevivido, assumem o dever de enunciar, na tentativa de presentificar a ausência dos mortos e os horrores do regime. O gênero consolida-se, dessa perspectiva, em um entre lugar, limiar situado nas fronteiras entre o biográfico, o autobiográfico, o autoficcional, o autodiscursivo e a ética coletiva de resgate de vivências insuportáveis, de forma a expor, também, a resistência oferecida pela linguagem. As lutas e estratégias do enunciador para empreender o possível resgate de acontecimentos, a trabalhosa e quase impossível tarefa enunciativo-discursiva de presentificação desse passado, o fazem assumir a condição de um sujeito histórico, social, cultural, coletivo, quando, a bem da verdade, ele é, sem qualquer álibi, uma das vozes a transitar entre as várias outras mobilizadas pelos discursos que se cruzam no enunciado.

Para fundamentar uma abordagem dialógica desse complexo discurso literário de resistência, que toma como motivo um passado que ecoa e persiste de forma trágica no presente, uma das chaves está na estilística do gênero romanesco, estilística dos gêneros da prosa literária ou estilística sociológica, constituída por meio da reflexão éticoestética que Mikhail Bakhtin (1895-1975) propôs e desenvolveu na quase totalidade de suas obras e, de maneira especial, em $O$ discurso no romance, escrito possivelmente entre 1934-1935, e aqui recuperado pela tradução de Paulo Bezerra. ${ }^{1}$ Esse ensaio oferece

Esse texto já estava traduzido para o português, fazendo parte da coletânea Questões de literatura e de estética. A teoria do romance (BAKHTIN, 1988). Existe uma nova tradução brasileira, feita diretamente do russo por Paulo Bezerra, cujo primeiro volume intitula-se Teoria do romance I: A estilística (BAKHTIN, 2015). 
elementos para uma reflexão a respeito de formas discursivas da prosa, de maneira a auxiliar o reconhecimento, nos discursos literários brasileiros de resistência, de estratégias encontradas pelo sujeito que resiste e que povoa seu enunciado de múltiplas vozes, do passado e do presente, harmônicas ou díspares, decisivas para a construção de um tempo-espaço e dos sujeitos que aí atuam e/ou atuaram.

$O$ discurso no romance é o ensaio que trata a prosa literária de maneira bastante original, especialmente no que se refere à capacidade desse gênero trazer para dentro do discurso, artisticamente constituído, o diálogo social das linguagens, o plurilinguismo (ou heterodiscurso como aparece na tradução mais recente), ${ }^{2}$ a luta entre as forças centrípetas, orientadas para a centralização verboideológica, para a singular unidade/ identidade de uma língua, e as forças centrífugas, constituídas pelas alteridades das múltiplas línguas/linguagens em movimento num dado momento histórico, produtoras da descentralização verboideológica. Ao discutir a necessidade de uma estilística sociológica ou estilística do discurso, capaz de dar conta de pontos de vista em constante tensão, conjunto de valores e maneiras de exprimi-los, esse texto de Bakhtin contribui decisivamente para uma reflexão a respeito de discursos contemporâneos de resistência, das vozes e posicionamentos axiológicos que os concretizam. Além das contribuições advindas diretamente desse trabalho, outras noções desempenharão aqui um importante papel, caso de enunciado, enunciado concreto, enunciação, autoria, texto e paratexto, fundamentais nesta discussão e que, no devido momento, serão explicitados e mobilizados.

\section{Faces de um discurso de resistência}

A partir dos pressupostos teóricos e metodológicos acima destacados, este trabalho discute resultados de pesquisas que dão continuidade à leitura, pela perspectiva dialógica do discurso ${ }^{3}$, de textos da literatura brasileira contemporânea, voltados para o período da ditadura militar dos anos 1960-19804. Dentre os muitos e significativos autores, cuja obra se caracteriza como prosa de resistência, o jornalista Bernardo Kucinski apresenta uma produção ficcional, assinada B. Kucinski, que se oferece como importante discurso literário contemporâneo de resistência e de enfrentamento do que ainda sangra, causa dor, repulsa, e até mesmo insegurança discursiva àqueles que sobreviveram ao terror e, também por isso, se impõem o dever de enunciar. A trilogia composta por $K$. Relato de

2 A diferença entre o termo plurilinguismo, mais difundido no que se refere à pluralidade de vozes que constituem um discurso, e heterodiscurso, é que este último pretende destacar o acento discursivo social. Em Breve glossário de alguns conceitos-chave, Paulo Bezerra, dentre outros aspectos, inclui a etimologia do termo em russo e afirma que na terminologia bakhtiniana "trata-se de um heterodiscurso social que traduz a estratificação interna da língua e abrange a diversidade de todas as vozes culturais em sua dimensão histórico-antropológica” [...] (BEZERRA, 2015, p.247).

A esse respeito, consultar Brait (2006).

4 Este artigo configura-se como um dos resultados do projeto de pesquisa Fundamentos e desdobramentos da perspectiva dialógica para a análise de discursos verbais e verbo visuais, que conta com apoio da bolsa PQ do CNPq (Proc. 303643/2014-5). Outros resultados podem ser verificados em Brait (2015, 2016a; 2016b). 
uma busca (KUCINSKI, 2011; 2012; 2014a; 2016a), Você vai voltar para mim e outros contos (KUCINSKI, 2014b) e Os visitantes (KUCINSKI, 2016b) configura um conjunto discursivo interdependente, concretizado por temática específica em relação aos anos de chumbo e pelas formas encontradas para que vozes institucionais e individuais se defrontem, se confrontem, aí incluída a voz do sujeito-enunciador e suas estratégias de variada e tensa presença. Nesse sentido, as três obras podem ser consideradas, em conformidade com a concepção bakhtintiana de linguagem, um enunciado concreto. ${ }^{5}$

O enunciado concreto, ao menos em seu acabamento provisório representado por essa trilogia, possibilita a observação dos valores em tensão que organizam o todo, delineando o acesso ao projeto discursivo do sujeito que, pela memória e pela linguagem, busca no passado respostas para acontecimentos escamoteados e sujeitos que "foram desaparecidos". A resistência ao discurso oficial, vigente e duradouro, caracteriza essa trilogia em que ficção, memória e resistência partem de fatos doloridos e concretizam uma dimensão estético-ideológica, uma rede discursivo fundamental para se pensar em um determinado momento da história brasileira. Por meio da evocação de diferentes vozes, o discurso literário de resistência se quer e se faz história (estória como diria João Guimarães Rosa) e História no sentido não ficcional. Essa tensa relação exige do discurso de resistência o apontar para fora, denunciando e expondo acontecimentos recuperados pela memória e, ao mesmo tempo, a incessante busca de uma materialidade linguístico-discursiva capaz de assumir essa dupla orientação característica do gênero. Dentre as múltiplas estratégias mobilizadas para esse fim, basta, por exemplo, observar a expressão "foram desaparecidos", utilizada ao longo da narrativa $K$. A substituição linguística do termo "desapareceram" por "foram desaparecidos" deflagra o embate entre duas vozes, entre dois discursos em tensão: o oficial, aquele que confere aos desaparecidos a condição de sujeitos ativos de uma ação (desaparecer), e o de resistência, que expõe, linguisticamente, a condição passiva, subjugada, sem escolha e sem defesa dos que foram existencialmente subtraídos. A troca, pela força da linguagem, expõe outro sujeito para a assombrosa ação, por meio da qual "as pessoas desapareciam sem deixar vestígios" (KUCINSKI, 2012, p.27). No segundo episódio de $K$, intitulado Sorvedouro de pessoas, o narrador afirma:

[...] Um senhor levantou-se, disse que viera de Goiânia especialmente para a reunião. Seus dois filhos, um de vinte anos e outro de apenas dezesseis, foram desaparecidos. Esse senhor gaguejava, parecia em estado catatônico. Foi o primeiro a usar a expressão "foram desaparecidos" (KUCINSKI, 2012, p.26, destaque do autor).

Esse é apenas um exemplo dos inúmeros recursos mobilizados para resistir linguística, discursiva, literária e existencialmente ao discurso oficial, na tentativa

O conceito de enunciado concreto, envolvendo enunciado/enunciação, está presente no conjunto da obra de Bakhtin e o Círculo. Além das obras-fonte, é possível recorrer a dois trabalhos que as discutem especificamente: Souza (2002) e Brait \& Melo (2010). 
de desmascarar e desmontar suas perversas estratégias de linguagem, de narração e explicação de "fatos", como se não bastasse sua incontestável força bruta. O que não é tarefa fácil, como se observa nessa trilogia de B. Kucinski.

A questão do gênero também é um aspecto fundamental para a compreensão dos discursos de resistência. A forte relação interna e temática entre gênero e realidade é um aspecto ao qual Pável Medviédev (2012), do Círculo de Bakhtin, trata com grande propriedade. Em um dado momento ele afirma:

Cada gênero é capaz de dominar somente determinados aspectos da realidade, ele possui certos princípios de seleção, determinadas formas de visão e de compreensão dessa realidade, certos graus na extensão de sua apreensão e na profundidade de penetração nela.

[...] Cada um dos gêneros [...] é um complexo sistema de meios e métodos e domínio consciente e de acabamento da realidade. [...] São as formas do enunciado [...] que desempenham o papel essencial na tomada de consciência e na compreensão da realidade. (MEDVIÉDEV, 2012, p.196 e p.198).

As considerações de Medviédev ajudam a entender as características do discurso de resistência aqui discutido e o gênero por ele assumido. Os três textos apresentamse como gênero que ocupa um entre lugar, uma fronteira, limiar entre o testemunho, a biografia, a autobiografia, a autoficção, tomando como matéria aquilo que se oferece como dor, terror, penumbra, no passado e no presente, implicando, constitutivamente, a dificuldade do fazer-se verbo. Enunciar significa enunciar-se no e pelo discurso que, nesse caso, embora fincado em raízes individuais, se oferece como metonímia de memórias, dores e perdas de outros eus disseminados no coletivo. Para dar existência e concretude a esse lugar genérico, ocorre, dentre outras significativas coisas, uma relação de grande originalidade entre o primeiro texto da trilogia, intitulado $K$, relato de uma busca, e o terceiro, Os visitantes. Essa especificidade, a ser esclarecida adiante, implicou uma decisão metodológica no sentido de um recorte, de forma que essas duas obras constituirão o corpus a ser trabalhado neste artigo, sem prejuízo do enunciado concreto de resistência formado pela trilogia.

$K$. é a história do desaparecimento de Ana Rosa Kucinski Silva, professora de Química da USP, irmã do autor na vida real, e seu marido, Wilson Silva, ambos militantes da Ação Libertadora Nacional (ALN), organização revolucionária comandada por Carlos Marighela. O pai, Meir Kucinski, escritor de língua ídiche, imigrante judeu polonês, que morreu em 1976, assume, na narrativa, o papel de narrador. Os visitantes, por sua vez, escrito cinco anos após a primeira edição de $K$., aparece como um post scriptum a $K$, uma espécie de pesadelo de um escritor, na medida em que várias das personagens, presentes na narrativa sobre a busca e o desaparecimento que motivaram a escritura de $K$., batem à porta de sua casa para reclamar de falhas, ausências, 
imprecisões. O narrador-personagem, no papel de escritor, também reclama muito da recepção da obra, como se observa no início do primeiro episódio, intitulado "A velha com o número no braço":

Atendi o interfone irritado. Muito irritado. Acabara de ler o jornal e, de novo, não havia referência alguma à novela, sequer uma notinha no canto da página. O porteiro disse: É uma senhora chamada Regina. Eu não me lembrava de nenhuma Regina. Perguntei-lhe o que ela queria. Diz que é sobre um livro, respondeu. Pensei: quem sabe, finalmente, uma jornalista querendo me entrevistar. E mandei subir. [...] O senhor é o escritor deste livro sobre a professora de química que desapareceu? Sem esperar minha resposta, continuou: Um livro forte e bem escrito, mas tem um erro muito feio que o senhor escritor precisa corrigir (KUCINSKI, 2016b, p.11-12).

Não apenas por essa senhora, mas por todos os demais que protagonizam cada episódio, a obra $O s$ visitantes poderia, aparentemente, indicar um relato de reclamações, com base na recepção da obra $K$. Observa-se, entretanto, que a questão motivadora de um novo discurso literário de resistência é o complexo discurso pautado entre invenção e acontecimento (história e estória), aspecto que, como já indicado, exerce papel fundamental no gênero, impondo, de certa forma, uma ética discursiva que enunciador deixa transparecer no ato verbal, no evento discursivo. Situado entre o individual e o coletivo, o passado e o presente, os acontecimentos e a memória ficcionalizada, o enunciador continua sob a égide dessa ética discursiva, que não cessa com o enunciado publicado. Ao contrário, a obra em circulação possibilita o surgimento de vozes discursivas configuradas justamente a partir da recepção, entendida como o coletivo dos leitores. Ao se colocar como parte desse coletivo, também o autor poderá, na condição de leitor de sua própria obra, sentir-se levado a rever detalhes de sua enunciação, relativizada, fragilizada ou contestada em diferentes pontos, por diferentes receptores. E parece que esse é o motor da existência dessa nova enunciação, desse novo enunciado intitulado Os visitantes, que tematiza acontecimento e invenção presentes em $K$., voltando como um incômodo bumerangue contra particularidades da escritura. E o enunciador, reinicia o jogo história e estória, mobilizando personagens a partir de supostos leitores de carne e osso.

O retorno de um escritor a uma de suas obras, de maneira a tematizá-la, explicála, justificá-la, não é exatamente uma novidade, encontrando outras ocorrências na tradição literária. Em Pós-escrito a O nome da rosa (ECO, 1985), por exemplo, escritor e medievalista italiano Umberto Eco se propõe a explicar "As origens e o processo de criação do livro mais vendido em 1984", como anuncia a capa. No primeiro tópico, intitulado "O título e o sentido", ele afirma: 
Desde que escrevi $O$ nome da rosa, chegam-me muitas cartas de leitores perguntando o que significa o hexâmetro latino final, e por que esse hexâmetro deu origem ao título. Respondo que se trata de um verso de De contemptu mundi de Bernardo Morliacense, um beneditino do século XII, que constitui uma variação sobre o tema do ubi sunt (como, posteriormente, o verso de Villon: mais où sont les neiges d'antan) com a diferença que, ao tópos corrente (os grandes de outrora, as cidades famosas, as belas princesas, tudo se esvai no nada), Bernardo acrescenta a ideia de que de todas as coisas desaparecidas só nos restam puros nomes. Recordo que Abelardo usava o exemplo do enunciado nulla rosa est para mostrar como a linguagem pode falar tanto das coisas desaparecidas quanto das inexistentes. Dito isso, deixo que o leitor tire suas próprias conclusões (ECO, 1985, p.7).

A escolha desse trecho inicial de Pós-escrito a $O$ nome da rosa não é um acaso, ${ }^{6}$ evidentemente. Nele, Umberto Eco, para responder a uma pergunta objetiva de um leitor, trata de algumas questões que estão em jogo nas obras em exame neste artigo. De um lado a questão prática dos leitores que, por meio de cartas (e poderiam ser e-mails, resenhas, entrevistas, etc.) se voltam para o escritor, tendo como objeto a obra publicada, de maneira geral, ou detalhes, curiosidades, indagações que, do ponto de vista dessa recepção, só ele poderá responder, esclarecer, explicar. Isso pode de fato ter acontecido a Bernardo Kucinski após a publicação de $K$., dada a força temática e discursiva da obra. Além disso, entretanto, a discussão, na obra de Eco, sobre o hexâmetro que deu origem ao título aponta ao menos para dois aspectos constitutivos e exacerbados em $K$. e Os visitantes, e que estão assim enunciados pelo autor de $O$ nome da rosa: “[...] de todas as coisas desaparecidas só nos restam puros nomes [...] a linguagem pode falar tanto das coisas desaparecidas quanto das inexistentes" (ECO, 1985, p.7). Sem dúvida é uma clara menção à história e estória, ficção e realidade, parâmetros que ao serem postos em diálogo disseminam-se pelo universo do discurso, constituindo e alterando escritor e leitor. Nesse sentido, Eco vai além de uma simples explicação do título, alertando o leitor para o fato de que, mesmo sendo um pesquisador, um medievalista, sua obra transita entre acontecimento e invenção. A partir daí, os demais tópicos (Contar o processo, Quem fala, Construir o leitor, dentre outros) seguem o ritmo erudito e didático de Eco, satisfazendo curiosidades dos leitores sobre os ingredientes de $O$ nome da rosa e do discurso literário em geral.

A obra Os visitantes, por sua vez, não é um escrito teórico-didático cuja finalidade seria explicar de forma lógica e racional a obra $K$., sua origem, seu processo de criação. Trata-se de um discurso de ficção que de fato (re)visita $K$., estabelecendo com ela uma interlocução polêmica. Por meio da estratégia de instauração de um enunciador-escritor

6 A única coincidência aqui não prevista, e que em certo sentido causa desconforto, é o termo rosa, nome próprio em Kucinski e comum e estratégico, do ponto de vista da discussão da linguagem, em Eco. 
e personagens-visitantes-leitores, a narrativa retoma personagens, questões, informações e, especialmente, a ética discursiva do escritor e possíveis esquecimentos constitutivos da memória, do discurso, da enunciação. O que, no fundo, não deixa de ser uma forma de (re)escrever o já escrito, o que foi enunciado, agora pela via de diferenciadas vozes da recepção que, em última análise, é uma dimensão temporal que transforma o autorcriador em leitor de sua própria escritura e o joga no redemoinho do heterodiscurso social, cultural, histórico que ele mesmo mobilizou. Espécie de continuidade do anterior, esse novo discurso literário de resistência se assume como enfrentamento do já dito, apontando para as dúvidas do sujeito enunciador, para o inacabamento e para as lacunas de seu dizer em relação a fatos, acontecimentos, dizeres que incomodaram profundamente os visitantes.

Ao expor as fraturas do dito, esse alter-discurso intitulado Os visitantes apresentase como o outro em relação a $K$., evidenciando armadilhas da linguagem e, de forma muito especial, as que minam o discurso que se debate entre memória individual e coletiva, assim como esquecimentos individuais e coletivos (será que há outra possibilidade no mundo da linguagem?). Nesse ponto, é preciso admitir que tanto Eco quanto Kucinski tematizam o processo de criação, sua produção, sua recepção e, da mesma forma que a matéria tratada pelo discurso literário de resistência, esse também se debate entre um acabado que não acaba. Sem assumir o gênero didático (bem longe disso), o enunciado de Kucinski implica um movimento de escuta triangulada entre escritor-obra-leitor, estabelecendo, para tanto, uma interlocução, uma interação polêmica entre as duas obras. Com isso, mais uma vez o discurso exibe, por outro ângulo, a força e importância da linguagem que pode falar tanto das coisas desaparecidas quanto das inexistentes.

Dada a singular relação entre $K$. e $O s$ visitantes, o enunciado concreto que configura o discurso de resistência será aqui composto por esses dois textos e, também, por seus paratextos autorais. A ideia do enunciado concreto, conforme concebido pelos pensadores do Círculo de Bakhtin, inclui o que se designa em outras perspectivas como paratextos, textos que se avizinham do texto principal, caso do título, subtítulos, dedicatórias, epígrafes, prefácio, posfácio, etc. e que, segundo vários teóricos, abrem caminho para o leitor adentrar os meandros do texto principal. No corpus específico escolhido para discussão neste artigo, e a partir do que foi apresentado até aqui, $K$. Relato de uma busca e Os visitantes se oferecem como alteridades constitutivas, um em relação à identidade do outro. A pergunta que se coloca, daqui em diante, é como diferenciar, nesse caso (se é que é possível), o texto principal de seu paratexto. A resposta a essa questão, em uma pesquisa que toma a relação texto-paratexto como uma das estratégias do discurso de resistência, deve considerar, inicialmente, alguns aspectos teóricos para, em seguida, analisar a paratextualidade e sua função no enunciado concreto que implica as duas obras.

Em termos teóricos, não apenas Gérard Genette (1982) tratou dessa questão e tem sido retomado ainda hoje em inúmeros trabalhos, mas muitos outros estudiosos se voltam para a importância dos diferentes paratextos escolhidos e/ou assinados pelo 
autor de determinada obra (paratextos autorais), assim como para os que fazem parte da produção do livro e são inseridos pelo editor (paratextos editoriais). As observações de Sabiá (2005, p.9), em artigo dedicado ao estudo do paratexto de algumas obras literárias mexicanas, ajudam a reiterar a ideia de que o segmento textual designado paratexto funciona como lugar e percepção de singularidades e camadas da interação autor/obra/ leitor/leitura.

Os leitores não entram diretamente em contato com o texto ficcional, mas entram de forma mediatizada. Essa mediatização se inscreve no marco global da lógica comunicacional e pragmática que subjaz a toda obra literária e se efetua por meio de uma série de instrumentos e estratégias que são compreendidas como "paratexto". Esse termo se refere a um conjunto de produções, da ordem do discurso e da imagem, que acompanham o texto, o introduzem, o apresentam, o comentam e condicionam sua recepção [...] [funcionando como] elos da estratégia de inscrição do autor e do leitor em uma situação interativa (SABIA, 2005, p.9, grifo do autor, tradução nossa). ${ }^{7}$

De certa forma, é como se o autor, tendo finalizado sua enunciação criadora, tendo posto um ponto final em seu discurso, ainda quisesse exercer controle sobre a situação, chamando a atenção do leitor, antecipando coisas que ele irá encontrar durante a leitura. $\mathrm{Ou}$, conforme o caso, interferindo no que foi narrado, por meio de um posfácio. Se assim é, o paratexto autoral não pode ser considerado algo descartável, uma excrescência em relação ao texto principal. Ele é uma intervenção do autor em direção a seu interlocutor, ele diz muito sobre o que o autor espera com esses acenos, com esses gestos significativos que antecipam o texto principal e sua leitura. Tratase de uma espécie de antessala interativa, por meio da qual o leitor adentra a obra. Assim sendo, pela perspectiva dialógica, considera-se que os paratextos, de fato, fazem parte do enunciado concreto. No caso do corpus deste artigo, os paratextos implicam, mesmo antes da leitura dos textos principais, enunciador e leitor/interlocutor em uma situação interativa instigante, funcionando como importante estratégia antecipadora das diversas faces da resistência discursiva. Os segmentos que se apresentam como paratextos apontam, como se verá, para a dimensão temática e para os embates com a linguagem, evidenciando a quase impossibilidade de dizer o que se oferece como (in)dizível. E é deles, enquanto estratégia dos discursos de resistência escolhidos, que este artigo se ocupa.

\footnotetext{
No original: Los lectores no entramos nunca en contacto con el texto novelesco de modo directo sino de forma mediatizada. Esta mediatización se inscribe en el marco global de la lógica comunicacional y pragmática que subyace a toda obra literaria y se efectúa por medio de una serie de instrumentos y estrategias que se engloban bajo el nombre de "paratexto". Tal término se refiere a un conjunto de producciones, del orden del discurso y de la imagen, que acompañan al texto, lo introducen, lo presentan, lo comentan y condicionan su recepción [...] ellos en una estrategia de inscripción del autor y del lector en una situación interactiva.
} 


\section{Paratexto, tradição e ruptura}

O texto $K$ está sendo trabalhado a partir de sua $2^{a}$ edição (KUCINSKI, 2012), publicada pela Editora Expressão Popular e que ainda não trazia o subtítulo Relato de uma busca. Nessa edição, antes de iniciarem-se os vinte e nove fragmentos, capítulos não numerados ou contos curtos, concisos, que tem como fio condutor um pai que tenta esclarecer o desaparecimento, nos anos 1970, sem deixar qualquer rastro, de dois jovens - sua filha e o marido -, destacam-se três paratextos autorais, significativos para a discussão das especificidades do discurso de resistência: uma dedicatória, três epígrafes e uma mensagem explicitamente dirigida ao leitor: Caro leitor. Nas edições posteriores, eles foram eliminados ou parcialmente colocados, assim como as ilustrações de Enio Squeff. Embora desempenhando um papel importante na produção de sentidos e na recepção (o artista fez os desenhos na condição de leitor) as ilustrações não serão consideradas neste artigo, uma vez que, apresentando-se ao longo do texto verbal, implicam verbo-visualidade, ou seja, uma articulação palavra/desenho que mereceria uma análise diferenciada no que diz respeito à produção de sentidos e a autoria do enunciado como um todo. ${ }^{8}$ Também não será tratada a sequência em que o autor agradece nominalmente aos que o apoiaram, incluindo sua mulher, com críticas e sugestões, uso do iídiche e dos mapas de ruas de Varsóvia, ajuda na fala dos desamparados.

Considerando que o discurso de resistência está sendo caracterizado, dentre outros aspectos, pela capacidade de mobilizar vozes sociais, também os paratextos serão observados sob esse ângulo, ou seja, enquanto heterodiscursos. Cada um por si e também em conjunto, eles enunciam, põem em movimento, discursos de resistência, no sentido de delinear o alvo a quem o enunciador vai se contrapor, o objeto da resistência, estabelecendo, ao mesmo tempo, uma parceria com o leitor. Trata-se de um diálogo velado, que qualifica o leitor como capaz de, antecipadamente, compreender importantes faces que motivam e sustentam o discurso que ele terá pela frente. Nesse momento, o enunciador acena com dizeres seus e de outros enunciadores, que ele traz para dentro de seu discurso, aí incluídas significativas vozes da tradição literária de língua portuguesa.

A dedicatória de $K$. (KUCINSKI, 2012, p.5) é o primeiro lugar em que a voz do autor criador se faz presença, por meio de delicados versos:

Às amigas, que a perderam;

De repente;

um universo de afetos se desfez.

\footnotetext{
A concepção de texto que fundamenta as reflexões aqui desenvolvidas tem origem nos trabalhos de Bakhtin e do Círculo. Eles entendem texto não apenas como expressão verbal (escrita ou oral), mas concretizado a partir de diferentes planos de expressão, o que possibilita o entendimento de texto visual, musical, etc. Além disso, o texto deve ser percebido como dimensão semiótico-ideológica, atualizada por um sujeito coletivo ou individual, situado, pertencente a um contexto, a uma cultura, em diálogo com interlocutores/discursos presentes, passados e futuros. Ver a respeito: Bakhtin (2016) e Brait (2016c).
} 
Sintoma da brutalidade dos acontecimentos, do desaparecimento, do abalo irreversível de um amplo universo do qual a desaparecida era protagonista, a dedicatória antecipa ao leitor o fato de que o discurso estará ancorado, ao mesmo tempo, na história pessoal e na História compartilhada pelo coletivo.

As epígrafes (KUCINSKI, 2012, p.11), por sua vez, também antecipam algumas faces do discurso que se inicia a partir da dedicatória, incluindo, desde já, a dificuldade do sujeito enunciador para concretizá-lo. Nesse sentido, discursos de três grandes escritores da língua portuguesa são convocados: João Guimarães Rosa, Fernando Pessoa e Mia Couto. Ainda que não se faça aqui uma análise detalhada de cada trecho, das particularidades das obras em que eles se encontram e de seus autores, assim como de seus significados nas narrativas de origem e no diálogo com tantas outras, é possível afirmar, a partir dessas epígrafes, que o discurso de resistência que o leitor terá pela frente, longe de ser unicamente um testemunho sobre uma época da história e da cultura brasileira, embora o seja com uma imensa força, lidará, também com muito vigor, com questões discursivas que dizem respeito a (im)possibilidades do narrar e da recuperação das vivências a serem narradas.

Inicialmente, cabe a um excerto de Grande sertão: veredas apontar para a construção e para as dificuldades do conhecimento pretendido pelo discurso:

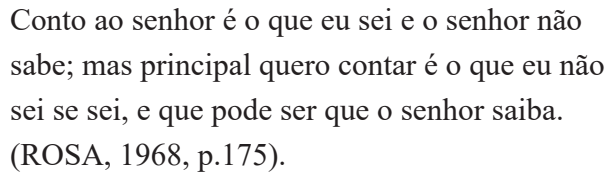

Um enunciador em primeira pessoa dirige-se diretamente a seu interlocutor, tratado por "senhor", para apresentar questões que dizem respeito ao contar, ao que ele quer narrar, às relações entretecidas entre quem conta e quem escuta/lê, especialmente no que se refere aos saberes e aos não saberes de cada um. Trata-se de um jogo de identidade/ alteridade/complementaridade entre sujeitos, objetos do conhecimento, autor/leitor, dimensões engendradas pelo discurso, dada sua natureza inescapavelmente interativa. Nesse sentido, o enunciador que acolhe a epígrafe, ao evocar a tradição, que coloca essas questões, também nela se insere. Ao fazer estória, se faz História, como confirmam as demais epígrafes.

Não é a dor que já não pode crer

Que m'oprime, nem a de não saber,

Mas apenas [e mais] completamente o horror

De ter visto o mistério frente a frente,

De tê-lo visto e compreendido em toda

A sua finalidade de mistério.

(PESSOA, 1969, p.460). 
A evocação de seis versos da XXVII estrofe do poema Mistério do Mundo (Primeiro Fausto, Primeiro Tema), de Fernando Pessoa, articula-se à primeira epígrafe para acrescentar, a partir de uma postura profundamente alegórica, a questão da dor, da opressão, do horror relacionado à visão e compreensão do mistério (impossível de ser explicado racionalmente), Uma visão filosófica, articulada ao testemunho e, ao mesmo tempo, à impossibilidade de enunciá-lo.

\author{
Acendo a história, \\ me apago a mim. \\ No fim destes escritos, serei, \\ de novo uma sombra sem voz. \\ (COUTO, 2015, p.14).
}

Pela terceira vez, um enunciador em primeira pessoa, dentro dos mesmos rastros do contar, da escrita e de seu papel, traz à tona a questão da história/estória que, ao iluminar-se pela voz do sujeito enunciador, apaga-o, tornando-o uma sombra sem voz, num movimento pendular entre o singular e o universal, o individual e o coletivo. O jogo existente entre os termos acendo, apago, sombra e a reiteração das formas do pronome de primeira pessoa - me e a mim - remetem, poética e tragicamente, à finalidade da escrita e à condição de ser ela, enquanto evento-voz, maior que o enunciador que a tornou luz, visibilidade, escuta. Ao recuperar Mia Couto, o sujeito enunciador de $K$. encontra mais um lugar na tradição literária para antecipar aspectos decisivos do enunciado com o qual o leitor se defrontará em seguida: a relação constitutiva entre contar uma história e atingir a História, ser história e, concomitantemente, ser História. Mas nessa terceira epígrafe, ele vai um pouco mais além. A localização do excerto na narrativa fonte permite observar duas coisas, como se verá a seguir:

Quero pôr os tempos, em sua mansa ordem, conforme esperas e sofrências. Mas as lembranças desobedecem, entre a vontade de serem nada e o gosto de me roubarem do presente. Acendo a estória, me apago a mim. No fim destes escritos, serei de novo uma sombra sem voz. (COUTO, 2015, p.14).

Os dois períodos anteriores ao trecho escolhido como epígrafe dizem respeito, explicitamente, à questão do querer de um enunciador, seu desejo de ordenar o tempo de esperas e de sofrências e, concomitantemente, à vontade própria das lembranças que o roubam do presente. Esses aspectos remetem aos movimentos internos da escritura. Sem dar espaço a esse trecho, o enunciador de $K$. vai direto ao movimento de claro/ escuro desencadeado pela relação escritura/escritor, interferindo graficamente na citação que não está transcrita como prosa, mas como verso. Ao inserir a citação em forma de poema e não de prosa, ele estabelece um diálogo co-autoral com o escritor citado, exibindo sua leitura interpretativa. Além do recorte do discurso de outrem, no fio de 
uma sintaxe que trabalha a favor do projeto discursivo em processo, o enunciador se inscreve no discurso citado, mudando seu gênero e, de uma certa maneira, assinando-o.

Se a linguagem é um elemento que possibilita o contar, desentranhando mundos, as três epígrafes, em sua proximidade temática, se dão como heterodiscursos, no sentido de vozes estético-sociais enunciadas a partir da diversidade da língua portuguesa (Brasil, Portugal e África), assim como do posicionamento axiológico de seus enunciadores. Escrevendo na mesma língua que se faz outra, cada sujeito enuncia relações com a vida, sociedade, cultura, memória, esquecimentos e, na condição de enunciadores, com as (im)possibilidades de (re)presentar inerentes à linguagem, aos discursos em circulação.

No conjunto dos paratextos de $K$., mais um deve ser destacado (ele não aparece na íntegra em edições posteriores), pela mesma força de antecipação revelada pelas epígrafes:

Caro leitor:

Tudo neste livro é invenção, mas quase tudo aconteceu. Deixei que lembranças fluíssem diretamente da memória, na forma como lá estavam, há décadas soterradas, sem confrontá-las com pesquisas, sem tentar completa-las ou lapidá-las com registros de época. Há referências a documentos em apenas duas histórias e somente como recurso narrativo.

Depois, valendo-me da fabulação, levei essas recordações a cenários imaginados; juntei situações ocorridas em tempos diferentes, algumas idealizei do quase nada e preenchi lacunas de esquecimento e os bloqueios do subconsciente com soluções inventadas.

Cada fragmento ganhou uma forma independente dos demais, não na ordem cronológica dos fatos e sim na exumação imprevisível desses despojos de memória, o que de novo me obrigou a tratar os fatos como literatura, não como História.

A unidade se deu através de K. Por isso, o fragmento que o introduz inicia o conjunto, logo após a abertura. E o que encerra suas atribulações está quase no final. A ordem dos demais fragmentos é arbitrária, apenas uma entre as várias possibilidades de ordenamento dos textos. (KUCINSKI, 2012, p.13).

Nesse contato explícito com o leitor, invocado textual e afetivamente (Caro leitor) (KUCINSKI, 2012, p.13), o autor criador da narrativa ficcional que em breve se iniciará, apresenta-se como a voz do autor empírico e afirma: "Tudo neste livro é invenção, mas quase tudo aconteceu". Daí em diante, de forma bastante didática explica a gênese e as características de sua enunciação, esclarecendo que recorreu muito pouco a documentos e, quando o fez, foi somente como recurso narrativo; que lidou com 
lembranças, recordações, memória, esquecimentos, bloqueios do subconsciente, mas que se socorreu da fabulação, criando cenários, situações idealizadas ou acontecidas em tempos diferentes, preenchendo lacunas e inventando soluções. Até mesmo a ordem do discurso, a articulação dos fragmentos é explicada como uma das possíveis, excetuando a entrada do pai que se dá em lugares precisos.

Antecipando-se às interpretações que poderiam ser realizadas pelo leitor, às leituras possíveis, uma voz de autoridade máxima, a do próprio autor, baliza o caminho, confundindo o leitor e empurrando-o para o um entre lugar que só o enunciado e o gênero por ele assumido podem esclarecer (se é que podem!): "Tudo neste livro é invenção, mas quase tudo aconteceu”. O jogo invenção e acontecimento (estória e história), explicado em detalhes nesse paratexto, na verdade parece mais uma forma de dizer que é impossível, pela linguagem, separar essas duas instâncias, fatalmente imbricadas, e de forma muito especial em narrativas que, no presente, procuram trazer o passado, abrir um espaço de linguagem em que acontecimentos devem ser falados para ganharem existência e serem compreendidos.

Em $K$., além dos paratextos apresentados, há uma particularidade na sintaxe textual do conjunto representado pelos vinte e nove fragmentos, com consequências enunciativas e discursivas que indiciam, sinalizam, formas de presença autoral diferenciada e suas relações alteritárias. O primeiro fragmento, intitulado "As cartas à destinatária inexistente" (KUCINSKI, 2012, p.15-17), e o último, "Post Scriptum " (KUCINSKI, 2012, p.177), estabelecem uma fratura sintático-semântica no conjunto, funcionando como moldura em relação aos demais. Ambos estão escritos em primeira pessoa do singular, no presente, destacados em itálico, localizados e datados: "São Paulo, 31 de dezembro de 2010". Esse destaque, sem dúvida, remete à autoria, que na luta pela possibilidade do dizer (entre o ser e a sombra), se introduz como mais uma voz, que se intromete para abraçar o narrado Os vinte e sete fragmentos emoldurados, enunciados em terceira pessoa por K., o pai, aquele que empreende e assina a busca, acolhem essa voz, esse heterodiscurso, que se diz a partir de um espaço e de um tempo que possibilitou a dolorosa enunciação. Se os paratextos em forma de dedicatória, epígrafes, etc., têm o objetivo de alertar o leitor sobre a natureza do que se enuncia e de quem enuncia, os dois fragmentos, inicial e final, acenam mais uma vez nessa mesma direção, sublinhando e embaralhando invenção e acontecimento.

Também em Os visitantes, a voz do autor se apresenta, em primeiro plano, por meio de duas epígrafes, uma dedicatória e um alerta ao leitor.

As epígrafes (KUCINSKI, 2016b, p.5) são poderosas assertivas, incluindo as fontes que as geraram. A primeira, "Desçamos e confundamos a língua deles, para que

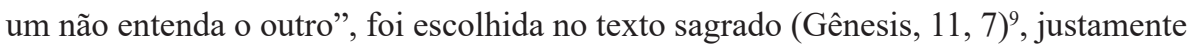
no momento em que se impinge aos homens a condição da incomunicabilidade, por oposição ao que seria uma língua única, de perfeito entendimento entre todos. A segunda, “Os fatos são escassos, as palavras numerosas” (S.Y. Agnon) vem de um dos mais

9 Disponível em: https://bibliaportugues.com/genesis/11-7.htm. Acesso em: 6 set. 2019. 
importantes escritores da literatura hebraica: Shmuel Yosef Agnon (1888-1970), prêmio Nobel de literatura em 1966. Tanto uma como a outra remetem à relação vida-linguagem, língua-incompreensão, excesso de palavras para a escassez de fatos, plurilinguismo em lugar de uma língua única. A referência à confusão disseminada entre os homens pela multiplicidade de línguas, de linguagens, se junta à reflexão de um grande escritor, cuja obra se caracteriza justamente por lidar, dentre outros importantes aspectos, com o conflito existente entre a linguagem e a vida. Não por acaso, o visitante que inicia a narrativa, protagonizando o primeiro conto, a primeira reclamação, é uma judia:

É sobre o holocausto, o senhor escritor escreveu que os alemães registravam todas as pessoas que matavam, mas isso não é verdade! [...] a maioria ia direto para a câmara de gás [...] Eu disse que lamentava. Ela disse: De que adianta o senhor escritor lamentar? O senhor escritor precisa corrigir; como está é um desrespeito aos milhões que foram desaparecidos (KUCINSKI, 2016b, p.12 e p.13).

A proximidade temática com as epígrafes de $K$. estabelece um forte parentesco sintático e semântico entre os dois textos. Destaca-se nesse segundo, entretanto, a ideia da incompreensão linguística, anátema divino, maldição da qual o homem não pode se libertar. Essa condição humana é agravada pelo fato de que quanto mais o homem lida com a linguagem, sua forma de compreensão e relação com a vida, mais a abundância das palavras ofusca os fatos. Dessa forma, o que resta a um autor criador, a um enunciador, senão lidar com palavras, socorrer-se da linguagem, mas, ao mesmo tempo, duvidar de seu discurso, constantemente colocado à prova, confrontado a fatos a ele inacessíveis, acontecimentos, lembranças, esquecimentos e até documentos? E é justamente isso que o leitor encontrará nos doze contos que compõem $O s$ visitantes. Eles remetem a fragmentos específicos de $K$, contestados pelos impiedosos visitantes que desafiam o escritor a ser fiel à realidade e/ou ao que eles consideram ser a realidade.

Esse novo discurso de resistência (nos vários sentidos aqui já indicados) é um discurso sobre o discurso, um enunciado sobre o enunciado, em certo sentido uma estratégia que o enunciador encontrou, pela metáfora dos visitantes, para enunciar e enunciar-se novamente, para expor-se, (re)visitando seu discurso anterior em busca das falhas, das faltas apontadas pela recepção (da qual ele faz parte) como uma nova oportunidade para tocar os famigerados fatos.

A página seguinte (KUCINSKI, 2016b, p.6) foi reservada unicamente à dedicatória. Bem embaixo, no que corresponderia à última linha da página, lê-se: "Em memória de Ana Rosa Kucinski Silva e Wilson Silva”. De forma explícita, portanto, esse novo discurso de resistência à ditadura militar brasileira, e da difícil tarefa de confrontá-la pela linguagem, está dedicado nominalmente às duas pessoas, muito próximas do autor, que foram desaparecidas, que motivaram $K$. Relato de uma busca e que, nesse momento da nova enunciação estão, por assim dizer, encontradas. O parentesco com o paratexto de $K$. evidencia-se por meio da enunciação mais direta, explícita, possibilitada 
por um novo tempo de desacobertamentos. Se em K. a obra está dedicada "às amigas que $a$ perderam", em Os visitantes, os sujeitos do desaparecimento estão nomeados e a expressão "em memória" lhes dá a visibilidade necessária para demonstrar que a busca teve um final.

Em Os visitantes há também uma espécie de alerta ao leitor (KUCINSKI, 2016b, p.9), afirmando e antecipando a natureza do relato que está por vir:

Tudo aqui é invenção, mas quase tudo aconteceu.

Como se observa, o gesto em direção ao leitor não vem mais, como em $K$, por meio de um texto de mais de meia página, intitulado "Caro leitor". Radicalmente mais enxuto, o paratexto caracterizador da narrativa aparece em formato de dois versos. A assertiva nele contida resume-se ao essencial do que estava na primeira linha do paratexto de $K$ : “"Tudo neste livro é invenção, mas quase tudo aconteceu". O formato assumido agora é ainda mais perturbador e certeiro, conferindo à narrativa, de forma antecipada, um pertencimento maior, e primeiro, ao campo da invenção: "Tudo aqui é invenção". Ao sujeito tudo, o mesmo da obra anterior, agora segue-se o dêitico aqui, em lugar de "neste livro". Essa diferença, fundamental do ponto de vista da enunciação, instala o enunciador em pleno espaço enunciativo. Da perspectiva linguística, a oração principal deixa claro que a narrativa está ancorada na invenção e que também o enunciador e sua natureza participam dessa instância ficcional. Essa assertiva, entretanto, após a vírgula que a separa do restante do período, é seguida da adversativa mas que a relativiza, a confronta e, de certa maneira, a desestabiliza, introduzindo o acontecimento no mundo da fabulação, ainda que modalizado pelo advérbio quase: "mas quase tudo aconteceu". Essa sinalização perturbadora, somada às epígrafes, embaralha mais uma vez invenção e acontecimento, ainda que nessa ordem, credenciando especialmente à linguagem do autor criador as dificuldades de expor as vivências. Caberá aos visitantes revelar as armadilhas do gênero assumido pelo escritor-personagem visitado e a ele, na condição de enunciador, de autor-criador, mobilizá-los no sentido de retomar a escritura da dor, do horror, tomando o novo discurso como mais uma tentativa de, pelo discurso literário, pela estória, exibir a história.

Também nesse novo discurso de resistência a questão da autoria se coloca para além das epígrafes e da dedicatória. Diferentemente de $K$., o relato se dá em primeira pessoa, colocando como enunciador o escritor, que simula ser o escritor empírico de $K$., mas que deixa abundantes marcas enunciativas e discursivas para o leitor perceber que ele é mais uma personagem, mais um visitante que se junta aos demais para discutir as (im)possibilidades de acontecimentos fazerem-se verbo, no caso, o enunciado concreto formado pelas duas obras e a tentativa de dizer, metonimicamente, os horrores ditatoriais.

O último fragmento, intitulado "Post mortem" (KUCINSKI, 2016b, p.76-83), também tem uma localização temporal diferenciada em relação ao anterior, intitulado " $\mathrm{O}$ visitante derradeiro" (KUCINSKI, 2016b, p.69-75), como aconteceu em K.: "Passaram- 
se dois anos". Nesse momento, além de fazer referência a fatos contemporâneos relacionados aos desparecimentos - "O instituto de Química deu-se conta de sua dupla ignomínia. Pediu desculpas públicas e ergueu um marco em homenagem à professora desaparecida. A Comissão da Verdade concluiu seu relatório sem nada descobrir" (KUCINSKI, 2016b, p.76), inclui, a transcrição, na íntegra, de entrevista concedida por agente da repressão "que sabe o que aconteceu", e que escreveu um livro contando tudo. O último parágrafo, entretanto, reinstaura o imaginário sobre a dúvida daqueles que, ainda hoje, não acreditam nos horrores perpetrados pelo regime militar:

Um truque. O jovem procurador disse que é um truque, que é mentira, que não aconteceu, que os corpos não foram incinerados num forno de assar melaço. Eu e minha ex sabíamos que era verdade. Sempre soubemos (KUCINSKI, 2016b, p.83).

\section{Considerações finais}

Os discursos literários de resistência aqui escolhidos poderiam mostrar muito mais do que se viu em termos de estratégias para, na e pela linguagem, fazer aflorar as atrocidades vividas ao longo dos anos da ditadura militar brasileira, assim como a dificuldade para apresentá-las, presentificá-las. O amplo conjunto da prosa brasileira de resistência, escrita durante e após os anos de chumbo, desempenha esse papel com grande qualidade, diversidade, poder de testemunho e força de documento estéticoexistencial. Muitos historiadores, críticos de literatura e analistas de discurso se debruçam sobre essas obras, dada a importância do conjunto para reflexões históricas, discursivas, literárias. Neste artigo, entretanto, a partir da perspectiva dialógica da linguagem, o objetivo foi mobilizar um aspecto desse discurso de resistência, recortado em paratextos. Esses segmentos textuais muitas vezes são ignorados pelo leitor, que nem os vê, no afã de chegar diretamente ao texto principal, ou pelo editor, que os acha abundantes, explicativos demais, desnecessários. Nesta leitura, o objetivo foi reconhecer neles uma das estratégias do discurso de resistência. ${ }^{10}$ Não uma estratégia ausente da tradição literária, mas um recurso discursivo presente em muitas outras obras e momentos e cuja função é ser um espaço antecipador (ou continuador) em que a linguagem sinaliza questões que serão (ou foram) tratadas, de forma explícita ou não, pelo texto considerado principal. O paratexto configurado pela dedicatória, pelas epígrafes, por exemplo, faz parte, também, de outros tipos de discurso, caso do discurso acadêmico, como demonstram teses, dissertações, artigos, capítulos e livros.

Os paratextos incluídos como corpus deste artigo, como foi possível observar, introduzem, metonimicamente, a temática a ser abordada, problematizando a relação

10 No texto Sobras e sombras de memórias da resistência (BRAIT, 2015), foram estudados os paratextos e suas funções na obra Zero, de Ignácio de Loyola Brandão (1976). 
vida/linguagem, invenção/acontecimento, tanto em $K$. como em Os visitantes, dando uma medida de como diferentes vozes são presentificadas e tecidas para construir o discurso de resistência representado por essas duas obras da trilogia de B. Kucinski. Esses paratextos, parte constituinte do enunciado concreto, ao mesmo tempo em que orientam, desnorteiam o leitor e o empurram para dentro de cada obra e da relação entretida entre elas. Ao adentrar as duas narrativas, o leitor perceberá que, embora cada uma se sustente como construção discursiva, a relação entre elas será a mesma estabelecida entre um texto e seus paratextos num dado enunciado concreto. Esta é, sem dúvida, a ruptura fundamental em relação ao que se concebe como paratexto.

$K$. Relato de uma busca é um enunciado sem o qual será impossível compreender a existência de $O s$ visitantes. Nesse sentido, $K$. pode ser considerado um paratexto em relação a essa segunda enunciação. Mas o vice-versa também é verdadeiro: $O s$ visitantes fazem o leitor voltar a $K$. e reler, de uma nova maneira, o que lá foi enunciado. Dadas as questões sobre autoria/alteridade constitutivas, ligadas aos heterodiscursos mobilizados, dentre eles os paratextos, e às dificuldade de conhecer e fazer conhecer fatos, o valor desse enunciado de resistência, representado pelas duas obras, faz do diálogo entre elas uma reflexão que vai além dos que foram desaparecidos para, pelo discurso literário de resistência, apontar para o hoje e para uma memória necessária e coletiva que parece escapar perigosamente.

\section{Agradecimentos}

Agradeço ao CNPq, Processo PQ 303643/2014-5, a possibilidade de desenvolver mais esta pesquisa.

BRAIT, B. Discourses of resistance: from paratext to text, or vice versa? Alfa, São Paulo, v. 63, n.2, p.243-263, 2019.

- ABSTRACT: This research aims to discuss the strategies used in discourses of resistance that confront the military dictatorship that ruled Brazil from the 1960s to 1980s and whose effects are still present today. These discourses never cease to surface in different spheres through different genres. Among them we find the literary discourse, which mobilizes individual and collective memory through documents and/or reports and is thus understood as one of the discourses that seek to unveil and make known the devastating consequences of the years of lead. Theoretically based on concepts offered by the dialogical perspective of discourse, $K$ : Relato de uma busca [K: A Search Report] (2012) and Os visitantes [The Visitors] (2016), written by journalist and writer Bernardo Kucinski, are analyzed as an articulated discourse sequence, insofar as the latter resumes the former, establishes a polemic interaction between them and makes it possible to find the values in tension that organize the whole sequence and design an outline of a discursive project and of the subject that utters it. For the purpose 
of this article, we underscore the dialogical relationship that is established between texts and paratexts, one of the strategies of the literary discourse of resistance that, through the establishment of voices, seeks answers to concealed events and to possible ways of making them present through language.

- KEYWORDS: Utterances of resistance. Paratext. Discourse stylistics. Heterodiscourse. Brazilian prose. Bernardo Kucinski.

\section{REFERÊNCIAS}

BAKHTIN, M. Notas sobre literatura, cultura e ciências humanas. Trad. Paulo Bezerra. São Paulo: Editora 34, 2017.

BAKHTIN, M. O texto na linguística, na filologia e em outras ciências humanas. In: BAKHTIN, M. Os gêneros do discurso. Trad. Paulo Bezerra. São Paulo: Editora 34, 2016. p.71-107.

BAKHTIN, M. O discurso no romance. In: BAKHTIN, M. Teoria do romance I: A estilística. Trad. Paulo Bezerra. São Paulo: Editora 34, 2015. p.19-241.

BAKHTIN, M. O discurso no romance. In: BAKHTIN, M. Questões de literatura e de estética: A teoria do romance. Trad. Aurora Fornoni Bernardini. São Paulo: Ed. da UNESP; HUCITEC, 1988. p.71-210.

BEZERRA, P. Breve glossário de alguns conceitos-chave. In: BAKHTIN, M. Teoria do romance I: A estilística. Trad. Paulo Bezerra. São Paulo: Editora 34, 2015. p.243-249.

BRAIT, B. La escena que retorna: memoria y escritura. In: ARAN, P. O. (org.). La herencia de Bajtín: Reflexiones y migraciones. Córdoba, Argentina: Centro de Estudios Avanzados, Universidad Nacional de Córdoba, 2016a. p.173-201.

BRAIT, B. Vozes entre as dobras da autoria. Revista da ABRALIN, Curitiba, v. 15, p.53-82, 2016b.

BRAIT, B. O texto nas reflexões de Bakhtin e o Círculo. In: BATISTA, R. O. (org.). O texto e seus contextos. São Paulo: Parábola, 2016c. p. 13-30.

BRAIT, B. Sobras e sombras de memórias da resistência. In: VÁZQUEZ, R. B.; SAMARTIM, R.; FEIJÓ, E. J. T.; BRITO-SEMEDO, M. (ed.). Estudos da AIL em Literatura, História e Cultura Brasileiras. Santiago de Compostela; Coimbra: AIL Editora, 2015. v. 1. p.43-52.

BRAIT, B. Análise e teoria do discurso. In: BRAIT, B. (org.). Bakhtin: outros conceitoschave. São Paulo: Contexto, 2006. p.9-31.

BRAIT, B.; MELO, R. de. Enunciado/enunciado concreto/enunciação. In: BRAIT, B. (org.). Bakhtin: conceitos-chave. São Paulo: Contexto, 2010. p.61-78. 
BRANDÃO, I. de L. Zero. 2. ed. Rio de Janeiro: Ed. Brasília/Rio, 1976.

COUTO, M. Terra sonâmbula. São Paulo: Companhia de Bolso, 2015.

ECO, U. Pós-escrito a O nome da Rosa. Trad. Letizia Z. Antunes e Álvaro Lorencini. Rio de Janeiro: Nova Fronteira, 1985.

FUKS, J. A resistência. São Paulo: Companhia das Letras, 2015.

GENNETE, G. Palimpsestes: La littérature au second degré. Paris: Ed. du Seuil, 1982.

KUCINSKI, B. K. Relato de uma busca. 4. ed. São Paulo: Companhia das Letras, 2016a.

KUCINSKI, B. Os visitantes. São Paulo: Companhia das Letras, $2016 b$.

KUCINSKI, B. K. Relato de uma busca. 3. ed. São Paulo: Cosac Naify, 2014a.

KUCINSKI, B. Você vai voltar pra mim e outros contos. São Paulo: CosacNaify, 2014b.

KUCINSKI, B. K. 2. ed. São Paulo: Expressão Popular, 2012.

KUCINSKI, B. K. São Paulo: Expressão Popular, 2011.

MEDVIÉDEV, P. N. Os elementos da construção artísticas. In: MEDVIÉDEV, P. N. O método formal nos estudos literários: introdução crítica a uma poética sociológica. Trad. Sheila C. Grillo; Ekaterina V. Américo. São Paulo: Contexto, 2012. p.193-207.

PAZ, O. O labirinto da solidão. Trad: Eliane Zagury. Rio de Janeiro: Paz e Terra, 1984. PESSOA, F. Obra poética. Rio de Janeiro: Aguilar, 1969.

ROSA, J. G. Grande sertão: veredas. 6.ed. Rio de Janeiro: José Olympio, 1968.

SABIÁ, S. Paratexto: títulos, dedicatorias y epígrafes en algunas novelas mexicanas. Espéculo: Revista de estudios literários, Madrid, n. 31, 2005. Disponível em: https:// webs.ucm.es/info/especulo/numero31/paratext.html. Acesso em: 6 set. 2019.

SOUZA, G. T. Introdução à teoria do enunciado concreto de Bakhtin/Voloshínov/ Medvedev. 2. ed. São Paulo: Humanitas, 2002.

Recebido em 9 de junho de 2018

Aprovado em 16 de novembro de 2018 